\title{
A Simulation Study of Typical Greenhouses in Beijing: PAR (Photosynthetically Active Radiation) Performances and Energy Consumption
}

\author{
Wang Yang ${ }^{1}$, Jiangtao $\mathrm{Du}^{2}$, Daoliang $\mathrm{Li}^{1}$ \\ ${ }^{1}$ College of Information and Electrical Engineering, China Agricultural University, Beijing, China \\ ${ }^{2}$ Scholl of Architecture, University of Liverpool, Liverpool, UK. jiangtao.du@liverpool.ac.uk
}

\begin{abstract}
Photosynthetically Active Radiation (PAR) and energy demand are critical factors to justify the performance of greenhouses in food and farming industry, which could be significantly affected by configurations and orientations of greenhouse. In Beijing, one typical greenhouse model with two types of roof (A-frame and Barrel-vault) and orientations (south-north; east-west) have been assessed using RADIANCE (ray-tracing packages) \& TRNSYS (energy package), in terms of PAR received at lower vertical planes of vegetation shelves, and heating and cooling demands in the whole space. Several key findings have been achieved, aiming to produce optimized design strategies to improve the availability of PAR for a faster growth of plant, and at the same time reduce energy consumption in greenhouses.
\end{abstract}

\section{Introduction}

Environmental and energy performances of greenhouse are receiving increasing attention in China, due to the growing activities of indoor farming (Tong et al., 2013). As the spectral range (wavelength) of solar radiation (400 to $700 \mathrm{~nm}$ ) that photosynthetic organisms are able to use in the process of photosynthesis, Photosynthetically Active Radiation (PAR) varies seasonally and changes based on the time of day and latitude (Hall, 1999). Similar to the wavelength of visual light, PAR is critically required for sustaining plant and vegetable growth (McCree, 1977). It can be normally found that the higher PAR can accelerate plant and vegetable growth. To investigate the availability of PAR is thus necessary when planning to build some indoor framing spaces and relevant facilities for growing vegetables and crops.

Apparently, orientation is one of most important environmental factors to determine the amount of solar gains (including PAR) and energy demand of the building (Pai et al., 2015). The solar radiation received across the surfaces of buildings is directly influenced by their orientations and the climate zones which the buildings are located in (Pai et al. 2015). In order to effectively apply an integrated passive design solution, to orient the buildings properly will always be the first consideration (Givoni, 1998). Next, as main factors that can determine energy consumption in buildings, the application of heating and cooling systems will have to include the impact of building orientation (Mardookhy et al. 2014). Pacheco et al. (2012) found that building orientation is one of the largest repercussions on the energy demand in buildings. It has been also concluded that optimizing both building orientation and shape can save the energy consumption up to 36\% (Aksoy et al., 2006). Spanos et al. (2005) found that a proper planning of orientation, location and landscape factors might potentially decrease the building energy demand by $20 \%$, via rising the quantity of solar radiation (daylight) entering an internal space. Using EnergyPlus simulations (EnergyPlus, 2018), Xu et al. (2012) produced some strategies of how to optimize building orientation to achieve energy efficiency in some representative cities in China. As for the greenhouse, similarly, the orientation and latitude can be significantly linked with the direct solar radiation transmissivity (Kurata 1993). One study investigated the effect of shape and orientation selection of a greenhouse on the energy demand and solar radiation availability, and experimentally validated the thermal model (Sethi 2009). In China, Chen et al. (2018) developed a computational model to determine the optimal orientation for solar greenhouse placed in various latitudes.

Moreover, the shape of building roofs with large glazing areas could be another critical factor affecting the solar radiation transmissivity (including daylight, PAR, etc.) in buildings (Sharples \& Lash, 2007). One early study (Navvab \& Selkowitz, 1984) examined fourteen roof structures under different sky conditions, and have achieved some key findings: 1) Most monitor roof systems were found to have a similar property of transmittance (direct light), which is much more sensitive to solar altitude than the pyramids, vaults and A-frames. 2) The A-frame roofs, however, got a higher transmittance for diffuse skylight (overcast sky) than the monitor systems. Later, a Canadian study (Laouadi \& Atif, 2001) showed that domes were the best shape for admitting sunbeam in winter (low altitude). It has found that in winter the barrel-vault roofs were more effective on the beam light transmitting than flat skylights with similar glazing attributes (Laouadi, 2005). For the greenhouse design, a numerical model of radiative PAR transfer was developed in order to achieve effective light distribution in a Barrel-vault greenhouse (Farkas et al., 2001).

When studying energy and environmental performances of greenhouses, in general, most of the studies were 
conducted based on an overall evaluation of indoor climates, thermal transfer, and solar gains (Ha et al., 2015; Ward et al., 2015). Few studies have been implemented to focus on the availability of PAR used for supporting the growth of vegetation, and how this value affects the whole energy performances including heating and cooling demands. For the typical thermal and solar modelling tools like EnergyPlus (EnergyPlus, 2018) and TRNSYS (TRNSYS, 2018), it is effective to simulate ambient environmental conditions and total energy consumption. However, given the calculation of solar irradiation (e.g. PAR) at a specific surface, it could be a hard task for them to achieve. On the other hand, the increasing indoor farming activities would require a more accurate estimation of PAR at specific surfaces in greenhouse, due to the aim to efficiently plan a proper 3D layout for setting vegetation.

Thus, in this article, a simulation study in a typical greenhouse in Beijing was presented based on the application of two packages: TRNSYS (energy and environmental modelling) and RADIANCE (ray-tracing modelling for solar and PAR) (RADIANCE, 2018). Two typical roof types and orientations have been assessed. Some design strategies for effectively growing vegetation and reducing whole energy consumption in similar greenhouses were produced.

\section{Building Model and Simulation}

\section{Description of Greenhouse Model}

The greenhouse studied was located in Beijing (Latitude: $39.9042^{\circ} \mathrm{N}$, Longitude: $116.4074^{\circ} \mathrm{E}$ ), China.

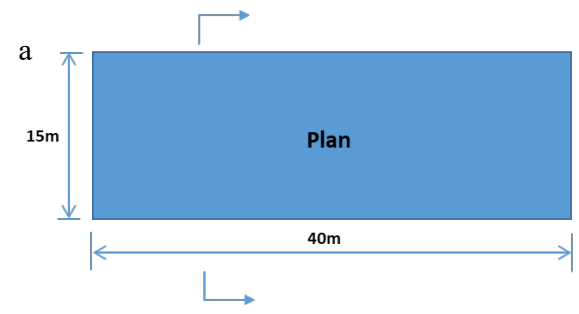

b A-frame (section)

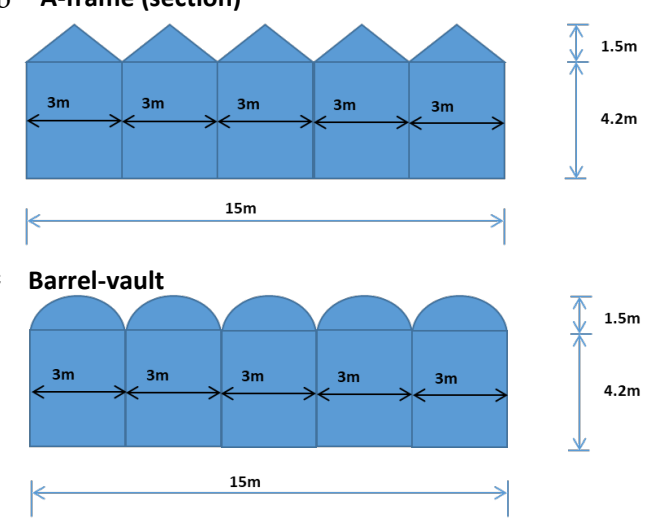

Figure 1: Greenhouse plan (a), and two sections with different roofs (A-frame (a) and Barrel-vault (b)).

Beijing has a humidity continental climate (www.weatherbase.com). The hottest month (July) in Beijing has an average temperature of $26^{\circ} \mathrm{C}\left(79^{\circ} \mathrm{F}\right)$ and the coldest is January at $-3.3^{\circ} \mathrm{C}\left(26^{\circ} \mathrm{F}\right)$. The average annual temperature is $12.8{ }^{\circ} \mathrm{C}$. Beijing receives 2,671 hours of annual sunshine time, with monthly percent possible sunshine ranging from $47 \%$ in July to $65 \%$ in January.

As shown in Figure1, the greenhouse has a rectangular plan (length $\times$ width: $15 \times 40 \mathrm{~m}$ ), and two typical types of sections varying in roof: A-frame (Sharples \& Lash, 2007) \& Barrel-vault (Laouadi, 2005). The sections were defined across the width (Figure 1). Each section has two parts including roof space (height: $1.5 \mathrm{~m}$ ) and normal space (height: $4.2 \mathrm{~m}$ ). Two orientations were studied as follows: the greenhouse length was aligned to northsouth or east-west. Therefore, in total, there are four cases studied, including A-frame \& south-north (A-sn), A-frame \& east-west (A-ew), Barrel-vault \& south-north (B-sn), and Barrel-vault \& east-west (B-ew).

\section{PAR Calculations}

In the field of plant science, PAR can be expressed by solar irradiance $\left(\mathrm{W} / \mathrm{m}^{2}\right)$ or photosynthesis photosynthetic photon flux $\left(\mu \mathrm{mol} / \mathrm{m}^{2} \mathrm{~s}\right)$ (Sun et al., 2017). The monochromatical relationship between the aforementioned two variables can be defined by the equation:

$$
P_{\lambda}=\frac{F_{\lambda} \lambda}{N_{A} h c}
$$

where $P_{\lambda}$ is the photon flux, $F_{\lambda}$ is the solar irradiance, $\lambda$ is the wavelength, $N_{A}$ is the Avogadro Number, $\mathrm{h}$ is the Planck constant, and $\mathrm{c}$ is the speed of light. In this study, PAR was displayed using solar irradiance $\left(\mathrm{W} / \mathrm{m}^{2}\right)$.

Produced for ray-tracing lighting/daylighting simulations (irradiance), RADIANCE (RADIANCE, 2018) can be used as a tool to calculate the global solar irradiance $\left(\mathrm{W} / \mathrm{m}^{2}\right)$ at a specific position and under various sky conditions. This study first adopted RADIANCE to predict the solar irradiance in the four greenhouse models mentioned above. PAR values were then achieved using an empirical equation (Dong et al., 2011):

$$
P A R=\eta_{0} Q
$$

where $\mathrm{Q}$ is global solar irradiance, $\mathrm{W} / \mathrm{m}^{2} ; \eta_{0}$ is the factor related to the location [Beijing has the $\eta_{0}=0.43$ (Bai, 2009)].

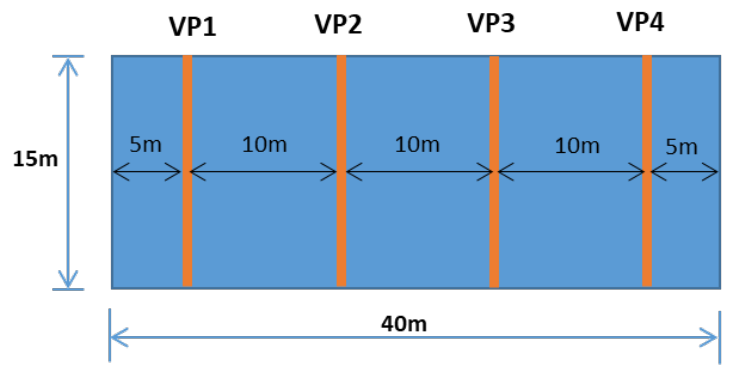

Figure 2: Plan view: four vertical planes for calculating $P A R$ in the greenhouse.

In this study, four vertical calculation planes were set up to evaluate PAR levels received at various positions across the width of greenhouse (Figure 2), including VP1, VP2, VP3 and VP4. The distance between two adjacent planes is $10 \mathrm{~m}$, whilst $5 \mathrm{~m}$ was set as a distance 
to the short walls. Vertically, the height of the planes was $0.3 \mathrm{~m}$ above the ground, which was used to specifically assess the PAR availability at the bottom area of these greenhouses. Although they are the most important positions for planting vegetation, clearly, these areas are regarded as the place with the lowest possibility to receive enough PAR levels. In addition, PAR availabilities were analysed using four typical periods relevant to the indoor farming, such as January (winter), April (spring), July (summer) and October (autumn) (Alados, et al., 1996).

\section{Building Energy Model}

TRNSYS (transient simulation programme) (TRNSYS, 2018), an advanced building energy modelling package, was employed to calculate indoor temperature and predict energy demand (heating and cooling) in this greenhouse. Overall heat transfer coefficients (u-values) of the greenhouse envelope were set as follows: 1.4 $\mathrm{W} / \mathrm{m}^{2} \mathrm{~K}$ (glazing wall and roof), $0.339 \mathrm{~W} / \mathrm{m}^{2} \mathrm{~K}$ (structures), and $0.313 \mathrm{~W} / \mathrm{m}^{2} \mathrm{~K}$ (floor). The g-value of glazing wall and roof was 0.589 . The annual heating and cooling demands have been calculated using various setpoints for heating and cooling systems based on the requirements of different types of plants and vegetables (Li, 1989; Brewster, 2018). As suggested by the guidance (Li, 1989; Brewster, 2018), the set-points of heating/cooling $\left(\mathrm{T}_{\text {heating }} / \mathrm{T}_{\text {cooling }}\right)$ in greenhouses were $22^{\circ} \mathrm{C} / 28^{\circ} \mathrm{C}$ (for normal plant and vegetables), $20^{\circ} \mathrm{C} / 32^{\circ} \mathrm{C}$ (typical thermophilic plant and vegetables), and $15^{\circ} \mathrm{C} / 20^{\circ} \mathrm{C}$ (typical plant and vegetables preferring the cool climate). All set-points have been applied in an annual energy consumption calculation. For all calculations, $0.21 / \mathrm{h}$ was used as the infiltration rate.

\section{Results and Discussions}

This section includes three parts: effect of roof type and orientation on PAR; effect of roof type and orientation on indoor air temperature and energy demand; discussions and implications.

\section{Effects of roof types and orientations on PAR}

As mentioned above, the variations of monthly average hourly PAR (Alados, et al., 1996) have been evaluated for four typical periods of winter (January: Figure 3), spring (April: Figure 4), summer (July: Figure 5) and autumn (October: Figure 6). These figures show the average of PAR across the four vertical planes shown in Figure 2.

Figure 3 indicates that the higher PAR can be found from 11:00 to 15:00 in winter. B-sn has the highest PAR level during this period while other three types have relatively lower values. With the orientation of south to north, both A-frame and Barrel-vault models receive the peak PAR at around 13:00; while the peak for models with orientation of east to west is found at 14:00. The peak PAR values are $5157 \mathrm{~W} / \mathrm{m}^{2}$ (B-sn), $4098 \mathrm{~W} / \mathrm{m}^{2}$ (Aew), $3907 \mathrm{~W} / \mathrm{m}^{2}$ (B-ew), and $3665 \mathrm{~W} / \mathrm{m}^{2}$ (A-sn). It is apparent that the PAR difference between B-sn and Bew significantly higher than that between two A-frame models.

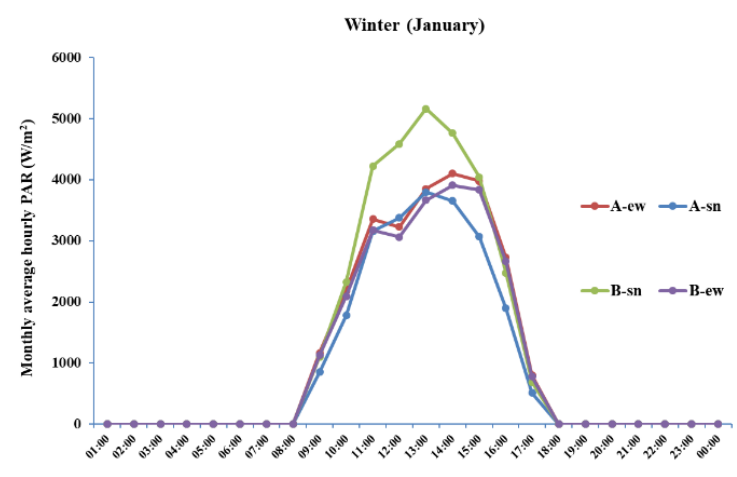

Tim

Figure 3: Monthly average hourly PAR in winter $\left(W / m^{2}\right)$.

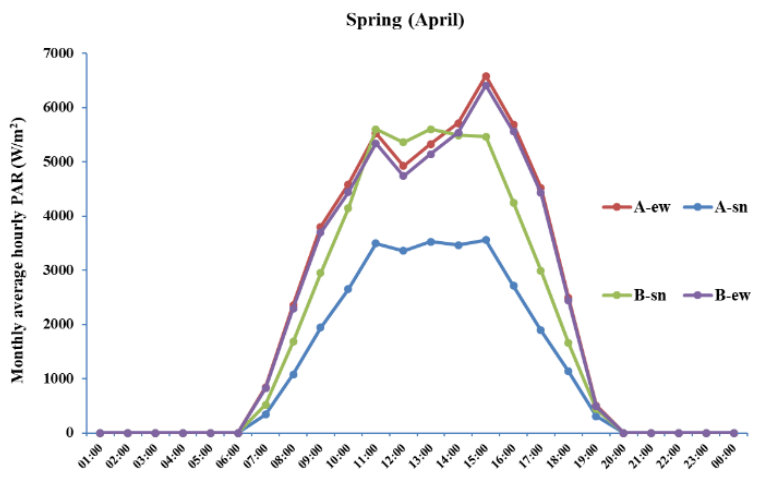

Time

Figure 4: Monthly average hourly PAR in spring $\left(\mathrm{W} / \mathrm{m}^{2}\right)$.

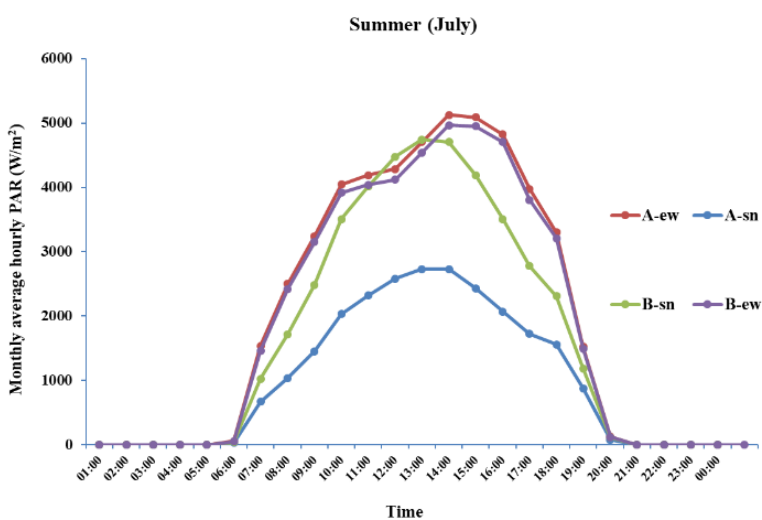

Figure 5: Monthly average hourly PAR in summer $\left(\mathrm{W} / \mathrm{m}^{2}\right)$.

Figure 4 and 5 show that PAR varies in a similar trend for spring and summer. It can found that most of the time A-ew has a very similar variation of PAR to B-ew. This might mean that the roof type would not take clear effect on PAR with the orientation of east to west. However, with the length aligned with south to north, Barrel-vault model can receive a much higher PAR that A-frame model at most of the time. In general, A-ew and B-ew have the highest PAR, while the lowest PAR can be found for A-sn. The B-sn can see the value in between. In spring, both A-ew and B-ew see the peak $\operatorname{PAR}(15: 00)>6000 \mathrm{~W} / \mathrm{m}^{2}$; while in the summer PAR of them peaks at 14:00 with a value ranging from 4900 
$\mathrm{W} / \mathrm{m}^{2}$ to $5200 \mathrm{~W} / \mathrm{m}^{2}$. However, both A-sn and B-sn have the peak PAR at 13:00 during the two periods.

In Figure 6, PAR variations of four models in autumn display some differences from winter. Before 11:00, Bew and A-sn have the highest and lowest PAR respectively. This period gives the similar PAR between A-ew and B-sn. Within the time from 11:00 to 15:00, Bsn achieves higher PAR than other models. However, the differences of PAR between B-sn and other models are comparatively smaller than the winter. A-ew and B-ew have the middle PAR levels whilst PAR of A-sn is still the lowest. After 15:00, A-ew and B-sn can bring in slightly higher PAR than A-sn and B-ew. Similalry, 13:00 and 14:00 are still the peak times for Barrel-vault and A-frame. The peak values are $5322 \mathrm{~W} / \mathrm{m}^{2}$ (B-sn), $4941 \mathrm{~W} / \mathrm{m}^{2}$ (A-ew), $4660 \mathrm{~W} / \mathrm{m}^{2}$ (B-ew), and $3702 \mathrm{~W} / \mathrm{m}^{2}$ (A-sn). Compared with winter, four greenhouses would generally receive higher PAR in autumn.

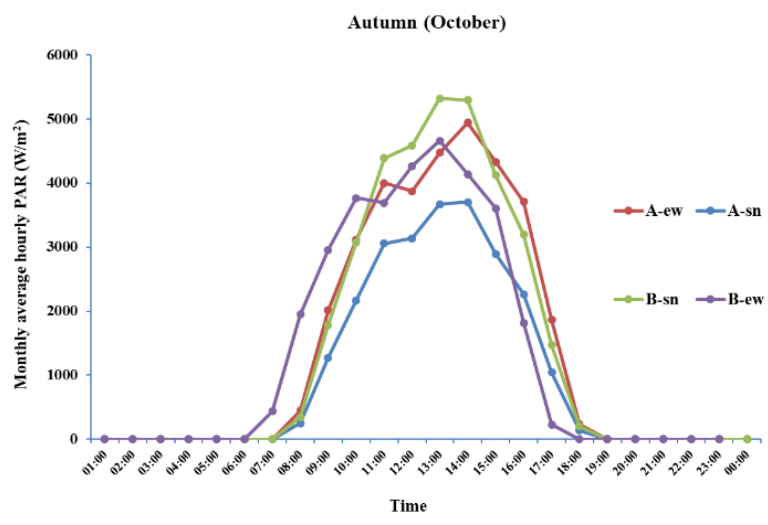

Figure 6: Monthly average hourly PAR in autumn $\left(W / m^{2}\right)$.

Table 1 gives the daily average of 24 monthly average hourly PAR values discussed in Figure 3-6. It can found that the lowest average PAR at vertical planes was delivered by the model of A-sn. Taking this model as a reference, relative differences of PAR of other models are given as follows: 1) Winter: 15\% for A-ew, 33\% for B-sn, 10\% for B-ew; 2) Spring: 79\% for A-ew, 57\% for B-sn, 74\% for B-ew; 3) Summer: 99\% for A-ew, 68\% for B-sn, $93 \%$ for B-ew; 4) Autumn: $40 \%$ for A-ew, $43 \%$ for B-sn, 33\% for B-ew.

Table 1: Daily average $\left(\mathrm{W} / \mathrm{m}^{2}\right)$ of 24 monthly average hourly PAR values.

\begin{tabular}{|c|c|c|c|c|}
\hline & A-sn & A-ew & B-sn & B-ew \\
\hline Winter & 920.7148 & 1058.097 & 1223.681 & 1012.662 \\
\hline Spring & 1228.248 & 2202.886 & 1923.09 & 2139.469 \\
\hline Summer & 1014.174 & 2022.154 & 1700.46 & 1957.343 \\
\hline Autumn & 983.5572 & 1375.536 & 1407.541 & 1312.995 \\
\hline
\end{tabular}

Effects of roof types and orientations on indoor air temperature and energy demand

Figure 7 indicates the distributions of indoor air temperature of four types of greenhouse with glazing wall and roof, structure and floor ( $\mathrm{U}$ values mentioned above), and without HVAC systems (unconditioned). The maximum and minimum temperatures of various models are $61.9{ }^{\circ} \mathrm{C}$ and $1.44{ }^{\circ} \mathrm{C}(\mathrm{A}-\mathrm{sn}), 74.4{ }^{\circ} \mathrm{C}$ and 1.44 ${ }^{\circ} \mathrm{C}$ (A-ew), $79.2{ }^{\circ} \mathrm{C}$ and $-1.05{ }^{\circ} \mathrm{C}$ (B-sn), and $72.9{ }^{\circ} \mathrm{C}$ and $1.13{ }^{\circ} \mathrm{C}$ (B-ew).

On the other hand, given typical types of plant and vegetable in Beijing region, the indoor farming using greenhouses would require three various temperature ranges ( $\mathrm{Li}, 1989$ ), such as $22{ }^{\circ} \mathrm{C} \sim 28^{\circ} \mathrm{C}$ for normal plant and vegetables (e.g. zucchini, loofah), $20{ }^{\circ} \mathrm{C} \sim 32{ }^{\circ} \mathrm{C}$ for typical thermophilic plant and vegetables (e.g. legume, tomato), and $15 \quad{ }^{\circ} \mathrm{C} \sim 20 \quad{ }^{\circ} \mathrm{C}$ for typical plant and vegetables preferring the cool climate (e.g. Chinese leaf, cabbage). Apparently, HVAC systems will have to be applied in the four greenhouse models to provide the plant and vegetable with a proper growing condition.

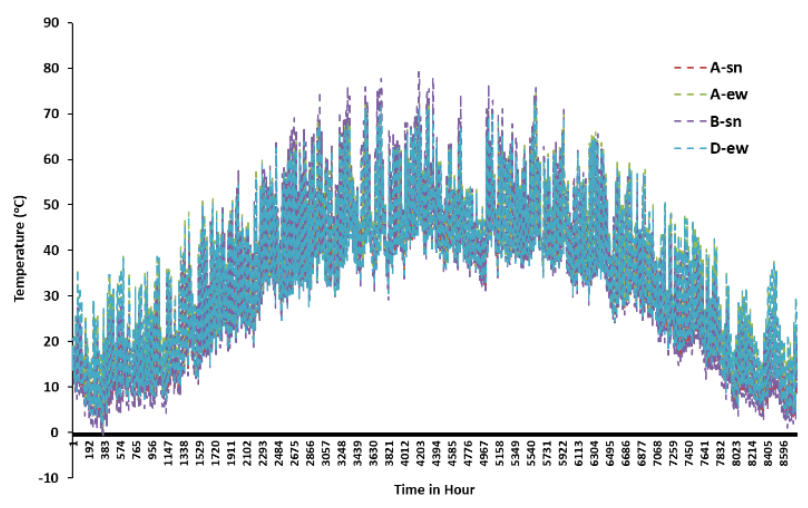

Figure 7: Distributions of indoor air temperature of four types of greenhouse (unconditioned).

For the set-point of $\mathrm{T}_{\text {heating }} / \mathrm{T}_{\text {cooling }}=22 / 28^{\circ} \mathrm{C}$, Figure 8-10 indicate the energy performances of four types of greenhouse. For annual energy demand (Figure 8), A-sn model would achieve the lowest value including heating $(69272.2 \mathrm{kWh})$ and cooling $(134313.9 \mathrm{kWh})$, whilst other three models have no big differences in between. Taking the overall energy demand of A-sn as a reference, relative differences of other models are 93\% (A-ew), 82\% (B-sn), and 95\% (B-ew). Similarly, only taking the heating demand of A-sn as a reference, relative differences of three models are $41 \%$ (A-ew), 62\% (B-sn), and $49 \%$ (B-ew). In addition, compared with A-sn model, relative differences of cooling demand of three models are 120\% (A-ew), 93\% (B-sn), and 119\% (B-ew). Clearly, A-sn can be regarded as a greenhouse model with the highest possibility to achieve energy efficiency.

Next, Figure 9 shows the heating demand of four types of greenhouse in January (winter) and October (autumn). Similar to annual heating demand, B-sn has the highest monthly heating demand in January (26915.5 kWh) and October (4831.4 kWh) among all four types. A-sn has the lowest heating demand compared with other three 
models. However, relative discrepancies of monthly heating demand between B-sn, A-ew, and B-ew are not significant in the two months.

Moreover, Figure 10 demonstrates the cooling demand of four types of greenhouse in April (spring) and July (summer). For all models, A-sn has the lowest monthly cooling demand in April (15891.4 kWh) and July (19154 $\mathrm{kWh}$ ). Similar to the heating demand, there are no clear differences of cooling demand between other three models. They have a monthly cooling demand ranging from 31849 to $34642.3 \mathrm{kWh}$ in both April and July.

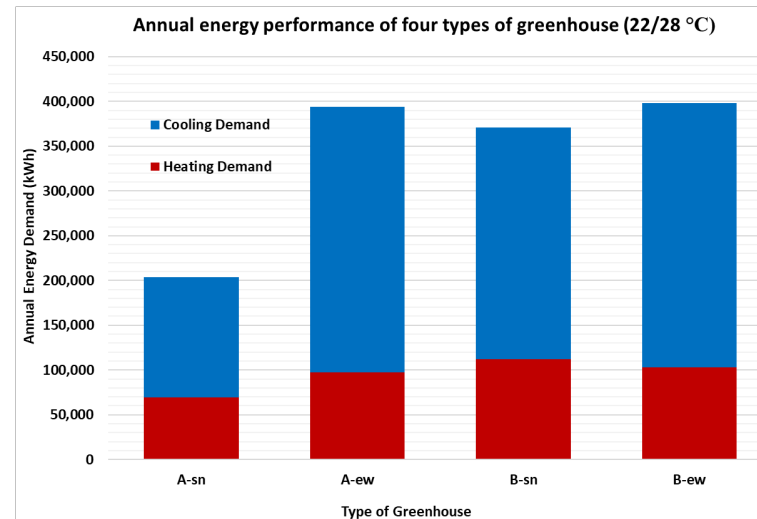

Figure 8: Annual energy performance of four types of greenhouse ( $T_{\text {heating }} / T_{\text {cooling: }} 22 / 28^{\circ} \mathrm{C}$ ).

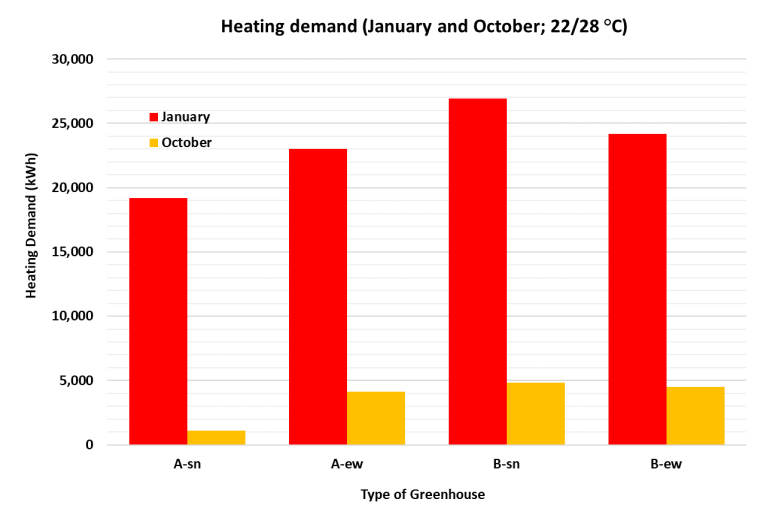

Figure 9: Heating demand (Jan \& Oct) of four types of greenhouse ( $T_{\text {heating }} / T_{\text {cooling: }} 22 / 28^{\circ} \mathrm{C}$ ).

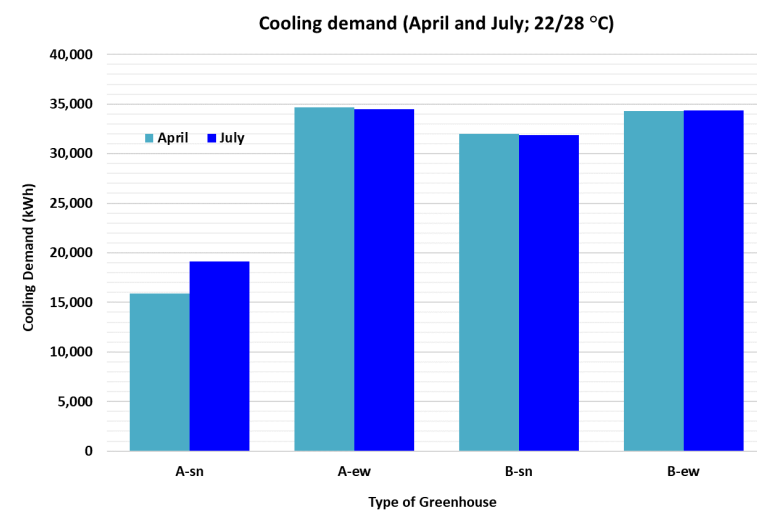

Figure 10: Cooling demand (April \& July) of four types of greenhouse ( $T_{\text {heating }} / T_{\text {cooling: }}: 22 / 28^{\circ} \mathrm{C}$ ).

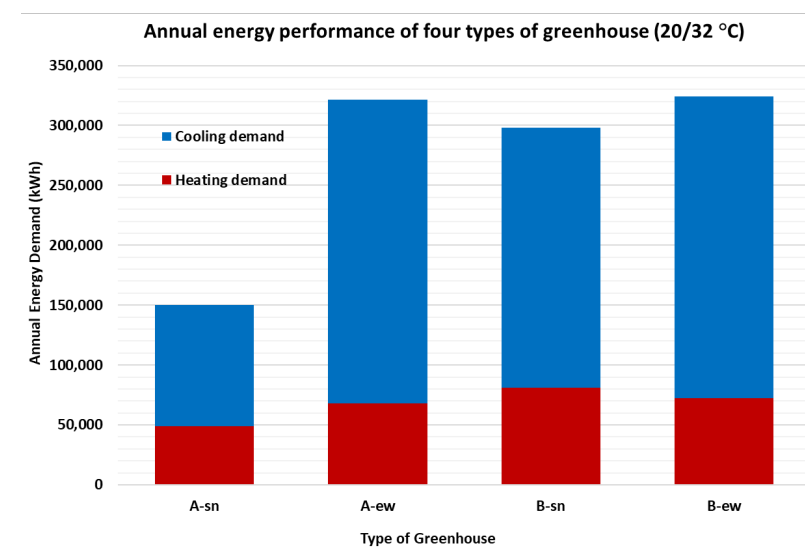

Figure 11: Annual energy performance of four types of greenhouse ( $T_{\text {heating }} / T_{\text {cooling: }}: 20 / 32^{\circ} \mathrm{C}$ ).

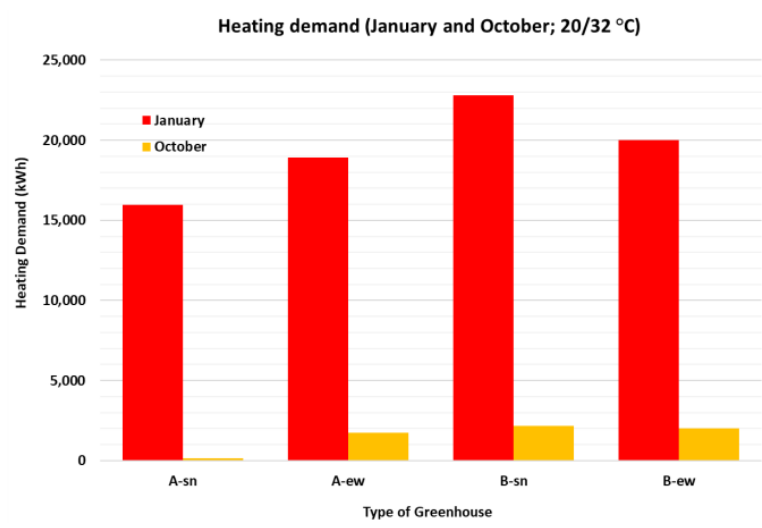

Figure 12: Heating demand (Jan \& Oct) of four types of greenhouse ( $T_{\text {heating }} / T_{\text {cooling: }}: 20 / 32{ }^{\circ} \mathrm{C}$ ).

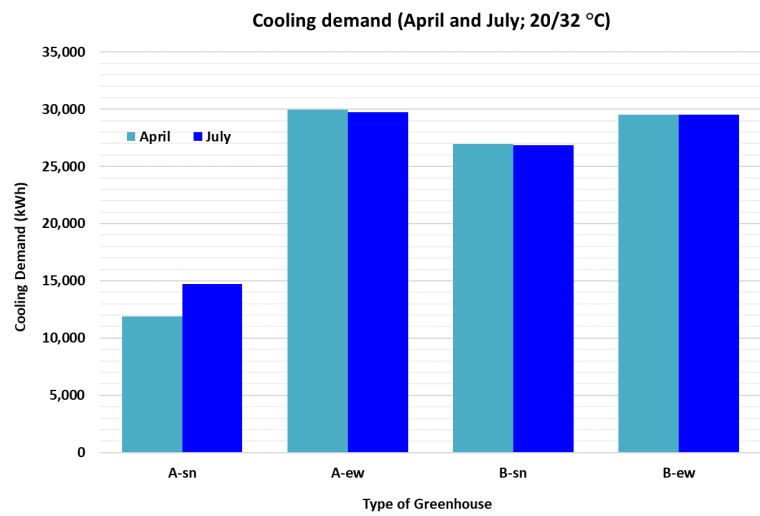

Figure 13: Cooling demand (April \& July) of four types of greenhouse ( $T_{\text {heating }} / T_{\text {cooling: }}: 20 / 32^{\circ} \mathrm{C}$ ).

For the set-point of $\mathrm{T}_{\text {heating }} / \mathrm{T}_{\text {cooling }}=20 / 32{ }^{\circ} \mathrm{C}$, Figure 11 indicates annual overall energy performances of four types of greenhouse. A-sn model would also achieve the lowest value including heating (49055.6 $\mathrm{kWh}$ ) and cooling (100861.1 kWh) applications; while similar energy performances can be found in other three models of A-ew, B-sn and B-ew. Taking the overall energy demand of A-sn as a reference, relative differences of other models are 114\% (A-ew), 99\% (B-sn), and 116\% 
(B-ew). For the heating demand only and taking the Asn as a reference, relative differences of other three models are 38\% (A-ew), 65\% (D-sn), and 48\% (D-ew). Also, relative differences of cooling demand between Asn and others are 152\% (A-ew), 115\% (D-sn), 149\% (Dew). Under this set-point, A-sn greenhouse can still give rise to the lowest energy consumption.

Next, Figure 12 presents the heating demand of four types of greenhouse for $\mathrm{T}_{\text {heating }} / \mathrm{T}_{\text {cooling }}=20 / 32{ }^{\circ} \mathrm{C}$ in January and October. Similar to the annual heating demand, D-sn has the highest monthly heating demand in January (22795.4 kWh) and October (2155.7 kWh) for all models, whilst the lowest heating demands in the two months are achieved by A-sn. However, there is no clear difference of heating demand between A-ew and B-ew in January and October.

Figure 13 demonstrates the cooling demand of four types of greenhouse for $\mathrm{T}_{\text {heating }} / \mathrm{T}_{\text {cooling }}=20 / 32{ }^{\circ} \mathrm{C}$ in April and July. Compared with other models, A-sn still has the lowest monthly cooling demand in April (11871.7 kWh) and July (14701.7 kWh). Other three models achieve much higher monthly cooling demand ranging from $26850.9 \mathrm{kWh}$ to $29755.2 \mathrm{kWh}$ in the two months. However, no big differences of cooling demand can be found between them.

For the lowest set-point of $\mathrm{T}_{\text {heating }} / \mathrm{T}_{\text {cooling }}=15 / 20{ }^{\circ} \mathrm{C}$, Figure 14-16 demonstrates the energy performances of four types of greenhouse. Given the annual energy demand (Figure 14), the lowest value including heating $(30527.8 \mathrm{kWh})$ and cooling $(211305.6 \mathrm{kWh})$ can be found for the model of A-sn. Taking the overall energy demand of A-sn as a reference, relative differences of other models are $80 \%$ (A-ew), 69\% (B-sn), and 82\% (Bew). Thus, there are only slight differences of energy demand between A-ew, B-sn and B-ew. Furthermore, taking the heating demand of A-sn as a reference, relative differences of other three models are $57 \%$ (Aew), $87 \%$ (B-sn), 68\% (B-ew). Similarly, relative differences of cooling demand between A-sn and others are 84\% (A-ew), 67\% (B-sn), 84\% (B-ew). Compared with the two cooling set-points $\left(28{ }^{\circ} \mathrm{C} \& 32{ }^{\circ} \mathrm{C}\right)$ discussed above, this set-point $\left(20^{\circ} \mathrm{C}\right)$ sees that the differences of cooling demand between A-sn and other models significantly dropped (e.g. from $152 \%$ to $84 \%$ ). This low cooling set-point could be clearly considered as the main cause.

Next, Figure 15 presents the heating demand of four types of greenhouse for $T_{\text {heating }} / T_{\text {cooling }}=15 / 20{ }^{\circ} \mathrm{C}$ in January and October. Similar to annual heating demand, B-sn has the highest monthly heating demand in January $(16720 \mathrm{kWh})$ and October $(1019 \mathrm{kWh})$ among all four types; while A-sn has the lowest values of $10227 \mathrm{kWh}$ (January) and $37.28 \mathrm{kWh}$ (October). Furthermore, relative discrepancies of monthly heating demand between B-sn, A-ew and B-ew are not big.

Last, for $\mathrm{T}_{\text {heating }} / \mathrm{T}_{\text {cooling }}=15 / 20{ }^{\circ} \mathrm{C}$ in April and July, Figure 16 demonstrates the cooling demand of four types of greenhouse. Compared with other mdoels, A-sn still has the lowest monthly cooling demand in April
(24059.5 kWh) and July (28974 kWh). A-ew and B-ew have higher cooling demands than A-sn in the two months: A-ew [42348 kWh (April) \& $45731 \mathrm{kWh}$ (July)] and B-ew [42155 kWh (April) \& 45914 kWh (July)]. It can be found the cooling performances of these two models are very similar. However, the monthly cooling demands of B-sn in April and July are just slightly lower than A-ew or B-ew.

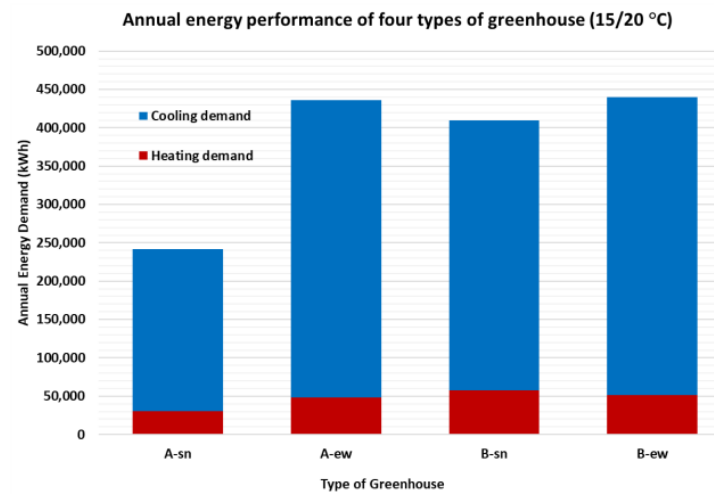

Figure 14: Annual energy performance of four types of greenhouse $\left(T_{\text {heating }} / T_{\text {cooling: }}: 15 / 20^{\circ} \mathrm{C}\right)$.

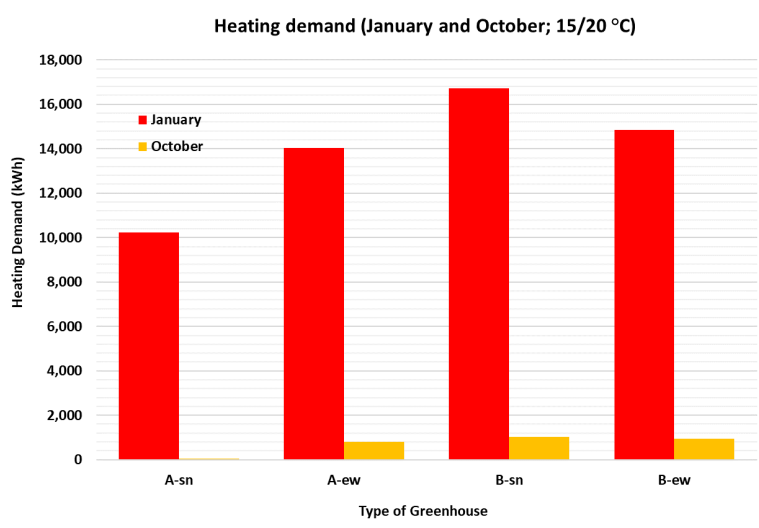

Figure 15: Heating demand (Jan \& Oct) of four types of greenhouse ( $\left.T_{\text {heating }} / T_{\text {cooling: }}: 15 / 20^{\circ} \mathrm{C}\right)$.

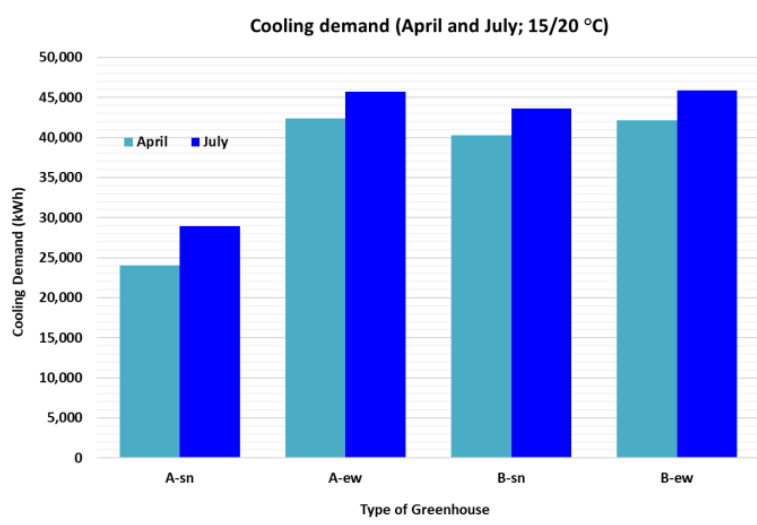

Figure 16: Cooling demand (April \& July) of four types of greenhouse ( $T_{\text {heating }} / T_{\text {cooling: }} 15 / 20^{\circ} \mathrm{C}$ ). 


\section{Discussions}

The PAR and energy performances in these greenhouse models can be explained on basis of two aspects: solar radiance transmittance and spatial volume, both of which are directly linked with the configuration design of greenhouse.

For the solar radiance transmittance, it is normal that the orientation (length: east to west) will generally deliver more solar radiances to the greenhouse surface than the orientation (length: south to north), especially at the roof. As mentioned in 'Introduction' (Laouadi \& Atif, 2001; Laouadi, 2005, Sharples \& Lash, 2007), roof configurations can significantly lead to various solar transmittances. The Barrel-vault roof can transmit more beam solar radiances in winter and autumn (lower solar altitudes). However, this might only work effectively with the orientation of south to north. For the A-frame, the orientation of east to west will receive higher solar radiances compared with the barrel-vault. The slope roof of such A-frame can allow more solar radiances into greenhouse in spring and summer (higher solar altitudes), whilst the slope facing north sky can block the least diffuse solar radiances compared with other models.

For the energy consumption, it seems that a combined effect of solar gains and spatial volumes can help explain various performances. For cooling demand, the indoor solar gain (linked to the solar radiance transmittance) is the key factor to justify the performance. Clearly, Aframe and Barrel-vault roof with the orientation of east to west would receive a much higher solar gain in spring and summer, which can lead to a relatively higher cooling demand. Furthermore, it is apparent that Barrelvault model has a bigger spatial volume than A-frame at the roof level. This larger space would generally bring in more heating demands, which could be a main reason to cause comparatively higher energy consumptions in autumn and winter.

\section{Conclusion}

This article has presented a simulation analysis of PAR availability and energy consumption for four greenhouses with different types of roof and orientation in Beijing, China. Heating and cooling demands with various set-points of $22{ }^{\circ} \mathrm{C} / 28{ }^{\circ} \mathrm{C}$ (normal plant and vegetables), $20{ }^{\circ} \mathrm{C} / 32{ }^{\circ} \mathrm{C}$ (typical thermophilic plant and vegetables), and $15{ }^{\circ} \mathrm{C} / 20{ }^{\circ} \mathrm{C}$ (typical plant and vegetables preferring the cool climate) have been calculated and analysed. Some findings that could be drawn from results and discussions include:

1) In general, the orientation would take significant impact on PAR availabilities and energy demands of the greenhouses with A-frame roof; while a comparatively lower effect of orientation can be found at the greenhouse with Barrel-vault roof.

2) It is interesting that the lowest PAR availability and energy demand can be found in the greenhouse with A-frame roof and the orientation of south to north, based on the solar analysis across four periods and three set-points.
3) To achieve a higher PAR availability, the analysis in winter and autumn would support the application of greenhouse with Barrel-vault roof and the orientation of south to north; in spring and summer, however, the greenhouse with A-frame roof and the orientation of east to west could deliver the optimal effect.

4) For the heating demand, the greenhouse with Barrelvault roof and the orientation of south to north would deliver the highest value according to annual and special periods' performances. However, there are no big differences between the greenhouses with A-frame roof and two orientations and the model with Barrel-vault roof and the orientation of east to west.

5) Given the cooling demand, with the orientation of east to west, the greenhouses with both A-frame and Barrel-vault roofs would give rise to the higher value than other models.

6) Compared with the set-points for normal plant/vegetables $\left(22{ }^{\circ} \mathrm{C} / 28 \quad{ }^{\circ} \mathrm{C}\right)$ and typical thermophilic plant/vegetables $\left(20{ }^{\circ} \mathrm{C} / 32{ }^{\circ} \mathrm{C}\right)$, the difference of cooling demand of plant and vegetables under cool climate $\left(15{ }^{\circ} \mathrm{C} / 20 \quad{ }^{\circ} \mathrm{C}\right)$ between the greenhouse with A-frame and southnorth (orientation) and other models would be dramatically reduced up to $72 \%$.

7) It is apparently found that there would be some conflicts between the requirements of PAR availability and energy saving for the design and planning of greenhouses in northern China. A balance will have to be considered during the early stage of design.

This research could benefit for planning the greenhouses and similar farming facilities in northern China. Future studies, including the field measurements for PAR and energy performances and the optimization strategies of greenhouses, will be carried out in the next stage.

\section{Acknowledgement}

This research was financially supported by China Agricultural University Excellent Talents Plan, and Fundamental Research Funds for the Central Universities in China (Grant No. 2018QC174). The authors also appreciate constructive and valuable comments provided by reviewers.

\section{References}

Aksoy, U., Inalli, M. (2006). Impacts of some building passive design parameters on heating demand for a cold region. Building and Environment 12(41): 17421754.

Alados, I. a., Foyo-Moreno, I. h., Alados-Arboledas, L. (1996). Photosynthetically active radiation: measurements and modelling. Agricultural and Forest Meteorology 78:121-131.

Bai, J. (2009). Calculating Photosynthetically Active Radiation in North China. Journal of Meteorology and Environment 25(2): 1-8. 
Brewster, J.L. (2018). Physiology of Crop Growth and Bulbing. CRC Press. Boca Raton (US).

Chen, C., Li, Y., Li, N., Wei, S., Yang, F., Ling, H., Yu, N., Han, F. (2018). A computational model to determine the optimal orientation for solar greenhouses located at different latitudes in China. Solar Energy 165: 19-26.

Dong, T., Meng, J., Wu, B., Du, X., Niu, L. (2011). Overview on the Estimation of Photosynthetically Active Radiation. Progress in Geography 30(9): 1125-1134.

EnergyPlus. https://energyplus.net/ [final access: 10 July 2018].

Farkas, I., Weihs, P., Biro, A., Laube, W., Eitzinger, J., Wojcicki, A. (2001). Modelling of radiative PAR transfer in a tunnel greenhouse. Mathematics and Computers in Simulation 56: 357-368.

Ha, T., Lee, I.B., Kwon, K.S., Hong, S.W. (2015). Computation and field experiment validation of greenhouse energy loads using building energy simulation (BES) model. International Journal of Agricultural and Biological Engineering 8(6): 116127.

Hall, D.O., Rao, K. (1999). Photosynthesis. Cambridge University Press. Cambridge (UK).

Kurata, K. (1993). Effects of greenhouse orientation and latitute on direct solar radiation transmissivity. Transactions of the Chinese Society of Agricultural Engineering 9(2): 52-60.

Laouadi, A. \& Atif, M. (2002). Prediction model of optical characteristics for barrel vault skylights. Journal of illuminating engineering society 31(2): 52-56.

Laouadi, A. (2005). Models of optical characteristics of barrel-vault: skylights: development, validation and application. Lighting research \& technology 37(3): 235-264.

Li, P.H. (1989). Low temperature stress physiology in crops. CRC Press. University of Minnesota, Minnesota (US)

McCree, K.J. (1977). Test of current definitions of photosynthetically active radiation against leaf photosynthesis data. Agricultural Meteorology 10: 443-453.

Mardookhy, M., Sawhney, R., Ji, S., Zhu, X., Zhou, W. (2014). A study of energy efficiency in residential buildings in Knoxville, Tennessee. Journal of Cleaner Production 85: 241-149.

Navvab, M. \& Selkowitz, S. (1984). Daylighting data for atrium design. Proceedings from the Ninth National Passive Solar Conference. Columbus (USA), September.
Pacheco, R., Ordonez, J., Martinez, G. (2012). Energy efficient design of building: a review. Renewable and Sustainable Energy Reviews 16(6): 3559-3573.

Pai, M.Y., Siddhartha, (2015). Effect of building orientation and window glazing on the energy consumption of HVAC system of an office building for different climate zones. International Journal of Engineering Research \& Technology 4(9): 838-843.

RADIANCE. https://www.radiance-online.org/ [final access: 10 July 2018].

Sethi, V.P. (2009). On the selection of shape and orientation of a greenhouse: Thermal modelling and experimental validation. Solar Energy 83: 21-38.

Sharples, S., Lash, D. (2007). Daylight in Atrium Buildings: A Critical Review. Architectural Science Review 50(4): 301-312.

Spanos, I., Simon, M., Holmes, K. (2005). Cost savings by application of passive solar heating. Structure Survey 23(2): 111-130.

Sun, Z., Hong, L., Liu, J., Shi, G. (2017). Estimation of photosynthetically active radiation using solar radiation in the UV-visible spectral band. Solar Energy 153: 611-622.

Tong, G., Christopher, D.M., Li, T., Wang, T. (2013). Passive solar energy utilization: A review of crosssection building parameter selection for Chinese solar greenhouses. Renewable and Sustainable Energy Reviews, 540-548.

TRNSYS. http://www.trnsys.com/ [final access: 10 July 2018].

Ward, R., Choudhary, R., Cundy, C., Johnson, G., McRobie, A. (2015). Simulation of plants in buildings; incorporating plant-air integrations in building energy simulation. Proceedings of BS2015: 14th Conference of International Building Performance Simulation Association. Hyderabad, India.

Givoni, B. (1998). Climate Considerations in Building and Urban Design. JOHN Wiley \& Sons, INC. New York, USA.

Xu, X., Yuan, D., Sha, H., Ji., Y., Xu, P. (2012). Energy consumption simulation of the prototypical building for optimizing the orientation of the building model in the simulated environment. Proceedings of the International Building Performance Simulation Association. Shanghai, China. 